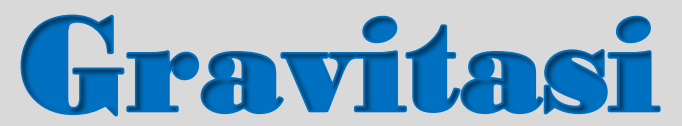

Journal available at: https://bestjournal.untad.ac.id/index.php/GravitasiFisika

\title{
Identifikasi Lapisan Akuifer di Kelurahan Petobo Kota Palu Menggunakan Metode Geolistrik Hambatan Jenis
}

\author{
(Identification of Aquifer Layer in Petobo Village, Palu City, using Geoelectric Resistivity \\ Method)
}

\author{
M. D. T. Musa $^{1 *)}$, S. Murniasih ${ }^{2)}$ \\ 1) Program Studi Teknik Geofisika, Jurusan Fisika Fakultas Matematika dan Ilmu Pengetahuan Alam Universitas Tadulako \\ 2) Program Studi Fisika, Jurusan Fisika Fakultas Matematika dan Ilmu Pengetahuan Alam Universitas Tadulako
}

\section{Info}

Article history:

Received: 08 June 2021

Accepted: 30 Desember 2021

Published: 31 Desember 2021

\section{Kata kunci:}

Akuifer

Geolistrik Hambatan Jenis

Konfigurasi Dipole-dipole

\section{Keywords:}

Aquifer

Geoelectric Resistivity

Dipole-dipole Configuration

\begin{abstract}
Abstrak.
Telah dilakukan penelitian dengan judul "Identifikasi Lapisan Akuifer di Kelurahan Petobo Kota Palu Menggunakan Metode Geolistrik Hambatan Jenis" bertujuan untuk mengetahui keberadaan serta kedalaman lapisan akuifer setelah likuefaksi. Penelitian ini menggunakan metode Automatic Array Scanning (AAS) dengan konfigurasi dipole-dipole serta diolah menggunakan Software Earthimager 2D dan Surfer 11. Hasil yang diperoleh menunjukkan lapisan dengan nilai hambatan jenis yang berkisar antara 30,92-77,3 $\Omega \mathrm{m}$ dengan nilai faktor formasi 2-5, diduga merupakan lapisan akuifer yang terdiri atas pasir dan kerikil ditunjukkan dengan warna hijau kekuningkuningan hingga warna kuning. Lapisan ini berada pada kedalaman $4 \mathrm{~m}$ hingga $38 \mathrm{~m}$ di bawah permukaan tanah dengan ketebalan berkisar 16-46 m. Lapisan akuifer mendangkal dan semakin menebal ke arah barat.
\end{abstract}

\section{Abstract.}

This research has been done with title "Identification of aquifer layer in Petobo village, Palu City, using Geoelectric Resistivity Method" aims to know the existence and depth of the layer of aquifer in Petobo village, Palu city after the liquefaction. The research uses Automatic Array Scanning $(A A S)$ method with dipole-dipole configuration and processed using Earthimager $2 D$ Software and Surfer 11. The results show a layer with the value of resistivity ranges between 30,92-77,3 $\Omega \mathrm{m}$ with a formation factor value of 2-5, allegedly a layer of aquifer consisting of sand and gravel shown in a yellowish green to yellow. This layer is at a depth of $4 \mathrm{~m}$ to $38 \mathrm{~m}$ below the ground surface with thicknesses ranging from 16-46 m. Aquifer layer is shallow and thickening towards the west.

*) e-mail: ochad_8795@yahoo.co.id

DOI: $10.22487 /$ gravitasi.v20i2.15531

\section{PENDAHULUAN}

Gempa Palu 28 September 2018 merupakan gempa yang disebabkan oleh sesar Palu-Koro [1]. Sesar Palu-Koro memanjang dari Utara (Palu) ke Selatan (Malili) hingga teluk Bone sepanjang $240 \mathrm{~km} \mathrm{[2].} \mathrm{Gempa} \mathrm{tersebut} \mathrm{merusak} \mathrm{struktur}$ dan infrastruktur, menelan banyak korban jiwa serta menimbulkan fenomena bencana lain seperti likuefaksi. Salah satu daerah yang terdampak likuefaksi akibat gempa Palu 28 September yaitu Kelurahan Petobo. Berdasarkan pengamatan dan hasil interpretasi yang dilakukan oleh LAPAN, diperkirakan bahwa total wilayah terdampak likuefaksi di Petobo ini adalah 175,65 Ha. Jumlah bangunan terpapar adalah 2.283 buah dimana 2.059 buah bangunan rusak dan 224 buah bangunan lainnya dikategorikan sebagai bangunan yang kemungkinan rusak [3].
Likuefaksi merupakan fenomena hilangnya kekuatan lapisan tanah akibat getaran gempa bumi. Pada saat mengalami getaran, air pori memberikan suatu tekanan di partikel-partikel tanah sehingga mempengaruhi kepadatan dari tanah tersebut [4]. Likuefaksi adalah jenis perubahan hidrologis coseismic yang dipicu oleh gempabumi yang bersifat merusak dan menelan korban jiwa [5]. Fenomena ini dapat terjadi apabila memenuhi syarat terjadinya likuefaksi, seperti lapisan tanah berupa pasir atau lanau, tanah jenuh air [4] serta memiliki muka air tanah yang dangkal [6]. Berdasarkan informasi yang diperoleh dari Lurah Petobo, muka air tanah di Kelurahan Petobo sebelum likuefaksi berada pada kedalaman \pm 2 meter. Dengan demikian, daerah ini memiliki potensi terjadinya likuefaksi. 
Gempa tersebut kemungkinan juga merubah lapisan struktur bawah permukaan seperti posisi lapisan air tanah (akuifer). Berdasarkan informasi, warga setempat memperoleh air pada kedalaman \pm 9 meter. Untuk melihat adanya perubahan posisi lapisan akuifer tersebut, perlu dilakukan penelitian. Salah satu metode geofisika yang dapat digunakan yaitu metode geolistrik hambatan jenis.

Metode geolistrik hambatan jenis digunakan untuk mempelajari keadaan bawah permukaan dengan cara mempelajari sifat aliran listrik di dalam batuan bawah permukaan bumi. Pada metode ini, masing-masing perlapisan batuan terpresentasikan oleh variasi nilai hambatan jenis. Nilai hambatan jenis setiap lapisan batuan ditentukan oleh beberapa faktor, diantaranya jenis material penyusunnya, kandungan air dalam batuan, sifat kimia air dan porositas batuan. Dengan mengetahui nilai hambatan jenis dari perlapisan batuan, dapat diduga jenis material atau batuan yang berpotensi sebagai lapisan air tanah (akuifer) [7]. Metode ini sebelumnya telah digunakan oleh Darsono [8], Purnama dkk [9], dan Irawati dkk [10] untuk mengetahui lapisan air tanah (akuifer) berdasarkan nilai hambatan jenisnya. Tujuan dari penelitian ini yaitu untuk mengetahui keberadaan serta kedalaman lapisan akuifer di Kelurahan Petobo Kota Palu setelah likuefaksi.

Berdasarkan Peta Geologi Tinjau Lembar Palu [11], formasi batuan yang terdapat di lokasi penelitian dan sekitarnya adalah alluvium dan endapan pantai yang terdiri dari kerikil, pasir, lumpur dan batugamping koral (Gambar 1). Alluvium ini merupakan jenis batuan yang paling muda.

Akuifer adalah suatu lapisan batuan yang mampu menyimpan dan meloloskan air secara ekonomis [12]. Sifat akuifer untuk dapat menyimpan airtanah disebut dengan kesarangan atau porositas, sedangkan sifat untuk meloloskan airtanah disebut dengan permeabilitas [13]. Akuifer dapat di temukan pada material-material yang belum terkonsolidasi yaitu pasir dan kerikil yang umumnya terdapat pada endapan alluvial, bekas sungai purba, dataran pantai dan lain-lain.
Meskipun sudah terkonsolidasi, batupasir dapat bertindak sebagai akuifer yang baik [14].

Ada dua macam akuifer yaitu akuifer tak tertekan (unconfined aquifer) dan akuifer tertekan (confined aquifer). Akuifer tak tertekan (unconfined aquifer) adalah akuifer yang terletak di bawah permukaan air tanah [15] dan berada di atas lapisan impermeable. Sedangkan akuifer tertekan (confined aquifer) adalah akuifer yang ditemukan di antara dua lapisan impermeable.

Pada eksplorasi hidrogeologi, pengukuran hambatan jenis dapat hitung menggunakan Persamaan (1) [16]:

$$
\rho_{w}=10000 / \mathrm{DHL}
$$

Berdasarkan Persamaan (1), dapat dihitung nilai faktor formasi (F) dengan menggunakan Persamaan (2) di bawah ini.

$F=\frac{\rho}{\rho_{w}}$

Tabel 1 berikut ini merupakan beberapa kesimpulan nilai faktor formasi (F) batuan dari beberapa studi hidrogeologi yang telah dilakukan.

Tabel 1. Nilai Faktor Formasi Batuan (Sumber: [16])

\begin{tabular}{ccc}
\hline F & Formasi & Aquiver/Aquiclude \\
\hline$<1$ & Clay & Aquiclude \\
$1-1,5$ & Peat, clayey sand atau silf & Aquiclude \\
2 & Silf - find sand & Poor to medium aquiver \\
3 & Medium sand & Medium to productive aquiver \\
4 & Coarse sand & Produktive aquiver \\
5 & Gravel & Higly productive aquiver \\
\hline
\end{tabular}

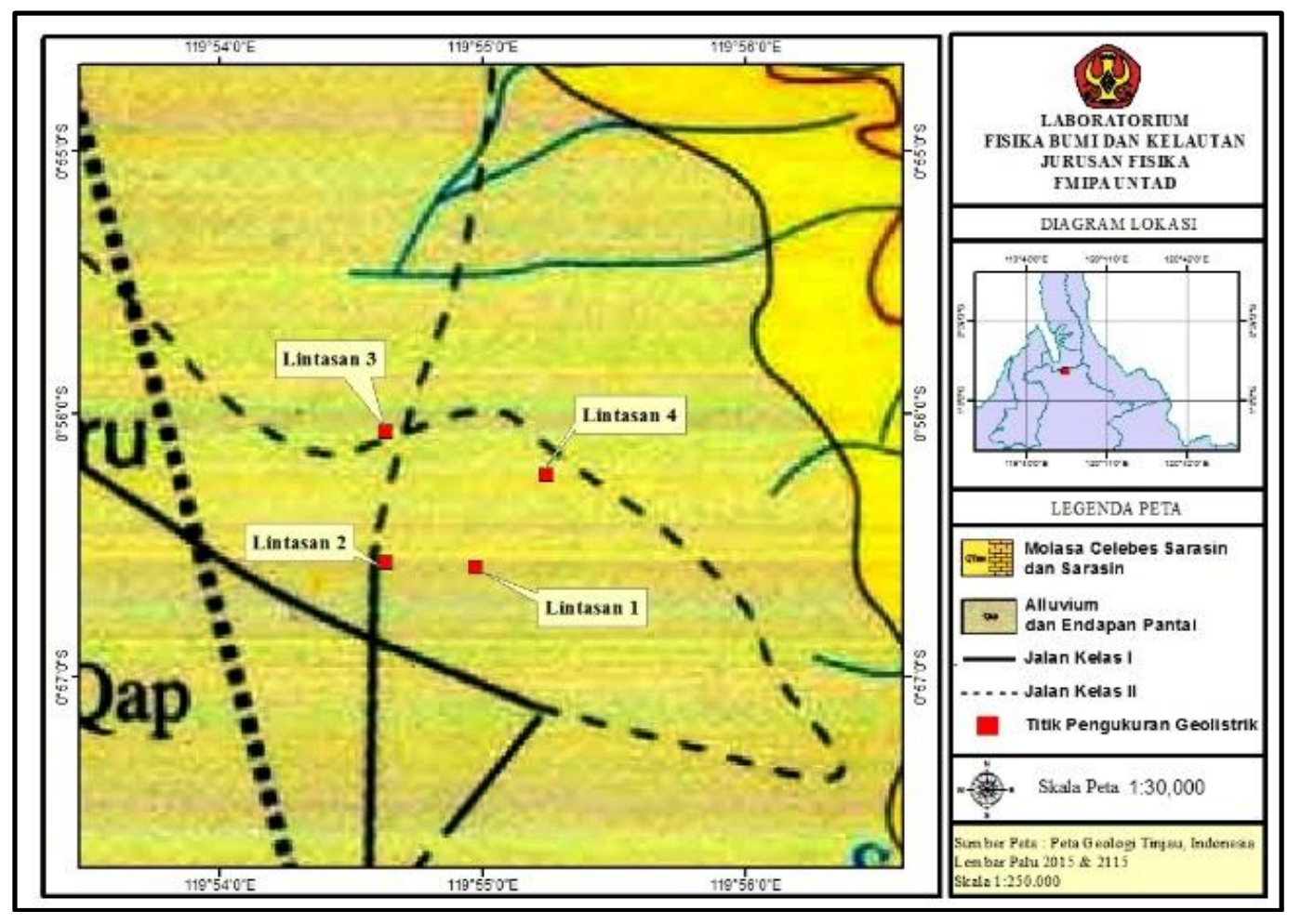

Gambar 1. Peta Geologi 
Metode geolistrik merupakan salah satu metode geofisika yang mempelajari sifat aliran listrik di dalam bumi dan bagaimana cara mendeteksi di permukaan bumi yang meliputi pengukuran potensial, arus dan medan elektromagnetik yang terjadi baik secara alamiah ataupun akibat injeksi arus yang dilakukan ke dalam bumi [17]. Pada metode geolistrik data yang diperoleh berupa nilai hambatan jenis, ketebalan dan kedalaman dari setiap lapisan batuan [18]. Salah satu metode geolistrik yang sering digunakan dalam pengukuran aliran listrik dan untuk mempelajari keadaan geologi bawah permukaan adalah metode geolistrik hambatan jenis.

Melalui hasil pengukuran arus dan beda potensial untuk setiap jarak elektroda tertentu, dapat ditentukan variasi harga hambatan jenis masing-masing lapisan di bawah titik ukur. Metode geolistrik hambatan jenis ini banyak digunakan dalam penentuan kedalaman batuan dasar dan pencarian reservoir air [19].

Hambatan jenis batuan dapat di ukur secara tidak langsung dengan menginjeksikan arus listrik ke dalam tanah melalui 2 elektroda $(\mathrm{AB})$ dan mengukur beda potensial antara dua titik lainnya (MN) (Gambar 2).

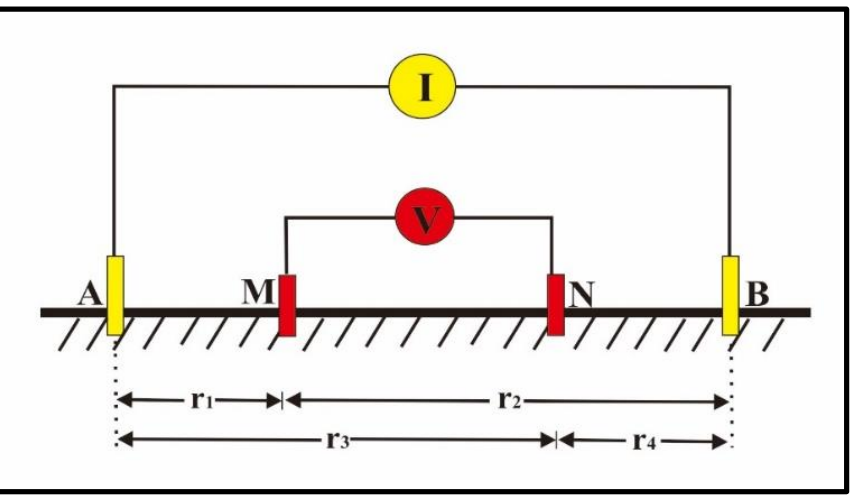

Gambar 2. Susunan Elektroda Arus dan Potensial Pada Pengukuran Metode Geolistrik [20]

Beda potensial yang terukur adalah:

$\Delta V=V_{M}-V_{N}=\frac{I \rho}{2 \pi}\left\{\left(\frac{1}{r 1}-\frac{1}{r 2}\right)-\left(\frac{1}{r 3}-\frac{1}{r 4}\right)\right\}$

Metode geolistrik hambatan jenis didasarkan pada anggapan bahwa bumi mempunyai sifat homogen isotropis. Arus yang dialirkan ke dalam bumi akan mengalir ke segala arah membentuk bidang equipotensial setengah bola [20]. Melalui asumsi ini, hambatan jenis yang terukur merupakan hambatan jenis yang sebenarnya dan tidak tergantung pada spasi elektroda. Namun pada kenyataannya bumi tersusun atas lapisan-lapisan dengan hambatan jenis yang berbeda-beda, sehingga potensial yang terukur merupakan pengaruh dari lapisan-lapisan tersebut. Oleh karena itu, harga hambatan jenis yang diukur seolah-olah merupakan harga hambatan jenis untuk satu lapisan saja. Hambatan jenis yang terukur sebenarnya adalah hambatan jenis semu $\left(\rho_{\mathrm{a}}\right)$ [21].

Besarnya hambatan jenis semu $\left(\rho_{\mathrm{a}}\right)$ adalah:

$\rho_{a}=K \cdot \frac{\Delta V}{I}$

Metode Automatic Array Scanning (AAS) adalah metoda geolistrik hambatan jenis yang melakukan pengukuran berulang-ulang serta berurutan dengan menggunakan kedalaman penetrasi tertentu [21]. Metode AAS sering digunakan dalam pengukuran geolistrik dengan berbagai konfigurasi, misalnya konfigurasi dipole-dipole.

Pada konfigurasi dipole-dipole, jarak antara pasangan elektroda arus sejauh a, begitu pula jarak antara pasangan elektroda potensial [22]. Elektroda arus dibuat tetap dan elektroda potensial digerakkan menjauhi kedua elektroda arus sejauh na sampai dengan jarak yang optimal [19]. Untuk meningkatkan kedalaman penetrasi, jarak antara sepasang elektroda arus dan potensial harus diperpanjang [22]. Perpindahan sepasang elektroda potensial ini dilakukan berulang-ulang sampai pada ujung bentangan (line) yang disurvei [19].

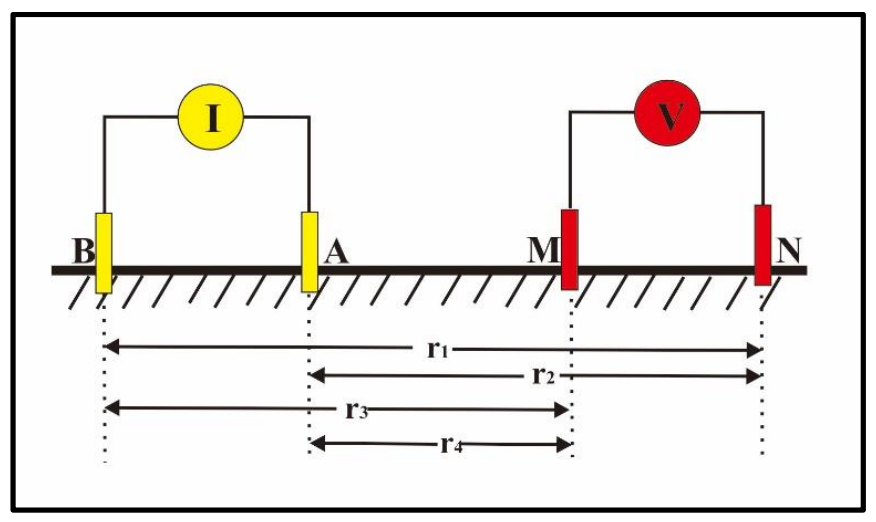

Gambar 3. Konfigurasi Dipole-dipole [20]

Berdasarkan Gambar 3, maka besarnya nilai faktor geometri konfigurasi dipole-dipole yaitu:

$$
\begin{gathered}
K=\frac{2 \pi}{\left(\frac{1}{r 1}-\frac{1}{r 2}\right)-\left(\frac{1}{r 3}-\frac{1}{r 4}\right)} \\
K=\pi a n(n+1)(n+2)
\end{gathered}
$$

\section{BAHAN DAN METODE}

Lokasi penelitian terletak di Kelurahan Petobo Kecamatan Palu Selatan Kota Palu yang terdampak likuefaksi. Secara geografis, lokasi penelitian berada pada posisi $0^{\circ} 566^{\prime} 3,93 "$ $0^{\circ} 56^{\prime} 38,70^{\prime \prime}$ LS serta $119^{\circ} 54^{\prime} 34,25^{\prime \prime}-119^{\circ} 55^{\prime} 17,96^{\prime \prime}$ BT. Gambar 4 di bawah ini merupakan peta lokasi daerah penelitian.

Peralatan yang digunakan dalam penelitian ini yaitu satu set alat Supersting R8IP, Palu, GPS (Global Positioning System), rollmeter (meteran), berfungsi untuk mengukur panjang lintasan dan spasi elektroda, dan konduktivitimeter. Pengukuran geolistrik hambatan jenis dilakukan untuk memperoleh gambaran tentang lapisan akuifer. Pengukuran ini menggunakan metode Automatic Array Scanning (AAS) konfigurasi dipole-dipole dengan jumlah lintasan sebanyak 4 lintasan. Setiap lintasan terdiri dari 56 elektroda dengan jarak spasi $4 \mathrm{~m}$ (Lintasan 1, 3, dan 4) dan $3 \mathrm{~m}$ (Lintasan 2). Panjang Lintasan 1, 3 dan 4 sebesar $220 \mathrm{~m}$, sedangkan Lintasan 2 sebesar $165 \mathrm{~m}$. 


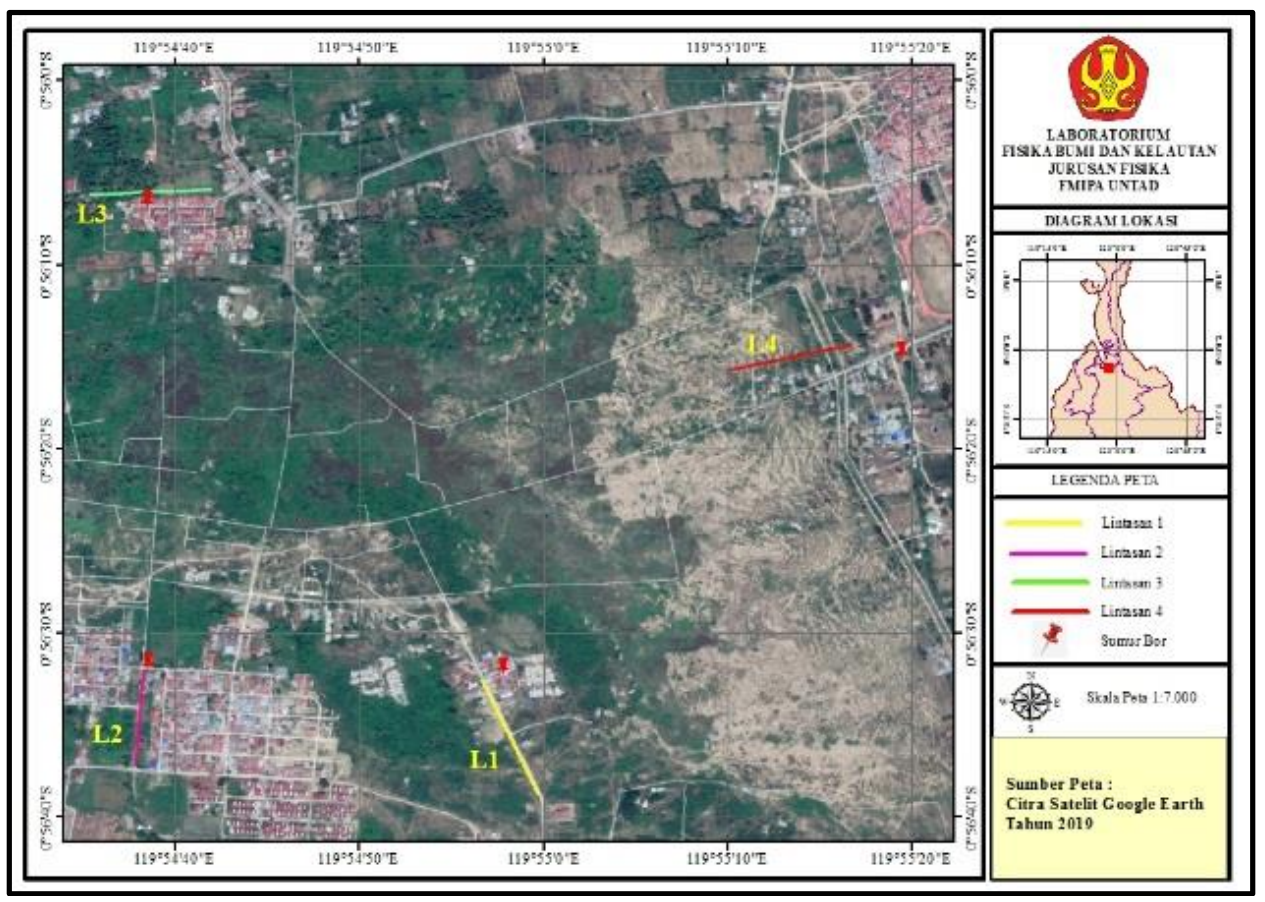

Gambar 4. Peta Lokasi Penelitian

Tabel 2 Hasil pengukuran DHL dan perhitungan hambatan jenis air pengisi pori

\begin{tabular}{cccc}
\hline Sumur & DHL $(\mathrm{S})$ & $\rho_{\mathrm{w}}(\Omega \mathrm{m})$ & Keterangan \\
\hline 1 & 684 & 14,62 & Sumur bor, dengan kedalaman $\pm 9 \mathrm{~m}$. Air jernih dan tidak berbau. \\
2 & 637 & 15,70 & Sumur bor, dengan kedalaman $\pm 9 \mathrm{~m}$. Air jernih dan tidak berbau. \\
3 & 641 & 15,60 & Sumur bor, dengan kedalaman $\pm 12 \mathrm{~m}$. Air jernih dan tidak berbau. \\
4 & 629 & 15,90 & Sumur bor, kedalaman $\pm 28 \mathrm{~m}$. Air jernih dan tidak berbau. \\
\hline
\end{tabular}

Pada saat pengukuran, digunakan $n=1$ sampai dengan $n=8$ dan spasinya di perbesar hingga 6a. Data yang diperoleh berupa nilai hambatan (V/I), faktor geometri (K), dan hambatan jenis semu $\left(\rho_{\mathrm{a}}\right)$ dengan total data yang diperoleh pada setiap lintasan sebanyak 762 . Selain data pengukuran yang direkam oleh Supersting $R 8 I P$, dilakukan juga pengukuran elevasi disetiap elektroda menggunakan GPS. Pengukuran ini dilakukan untuk memperoleh gambaran topografi pada setiap lintasan. Selanjutnya, untuk mendukung tahap interpretasi, dilakukan pengambilan sampel air di 4 sumur bor milik warga, lalu mengukur Daya Hantar Listrik (DHL) air yang digunakan untuk menghitung nilai hambatan jenis air pengisi pori $\left(\rho_{\mathrm{w}}\right)$ menggunakan Persamaan (1). Kemudian, nilai hambatan jenis air pengisi pori $\left(\rho_{\mathrm{w}}\right)$ tersebut digunakan untuk menghitung nilai faktor formasi batuan menggunakan Persamaan (2).

\section{HASIL DAN PEMBAHASAN}

Adapun hasil pengukuran DHL air dan perhitungan hambatan jenis air pengisi pori dapat dilihat pada Tabel 2. Software yang digunakan untuk mengolah data yaitu EarthImager 2D dan Sufer 11. Softawre EarthImager 2D digunakan untuk melakukan proses inversi, dengan data masukan yang terekam di Supersting R8IP. Hasil pengolahan berupa 3 penampang 2D nilai hambatan jenis. Penampang yang kedua menunjukkan nilai hambatan jenis semu hasil perhitungan (calculate apparent resistivity pseudosection), dan penampang yang ketiga menunjukkan nilai hambatan jenis sebenarnya (inverse resistivity section). Model yang diperoleh melalui proses inversi akan memiliki nilai root mean squared error (RMS). Iterasi dilakukan beberapa kali untuk menurunkan nilai error yang ada.

Berikut tampilan hasil pemodelan 2D hambatan jenis bawah permukaan.

\section{Lintasan 1}

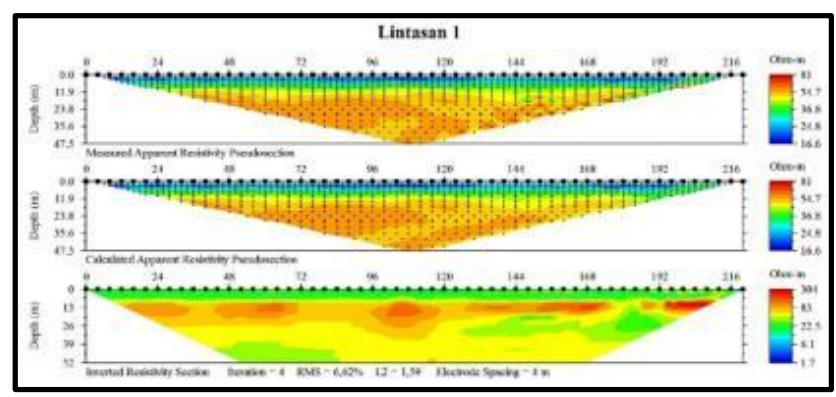

Gambar 5. Penampang 2D Hambatan Jenis Lintasan 1

Penampang 2D Lintasan 1 (Gambar 5) menunjukkan bahwa nilai minimum hambatan jenis semu yang terukur dan terhitung sebesar $16,6 \Omega \mathrm{m}$ dan maksimum $81 \Omega \mathrm{m}$ dengan nilai hambatan jenis sebenarnya sebesar $1,7 \Omega \mathrm{m}$ sampai $304 \Omega \mathrm{m}$. 
Nilai kesalahan yang diperoleh dari selisih hasil pengukuran dan hasil perhitungan sebesar $6,62 \%$ dengan 4 kali iterasi.

\section{Lintasan 2}

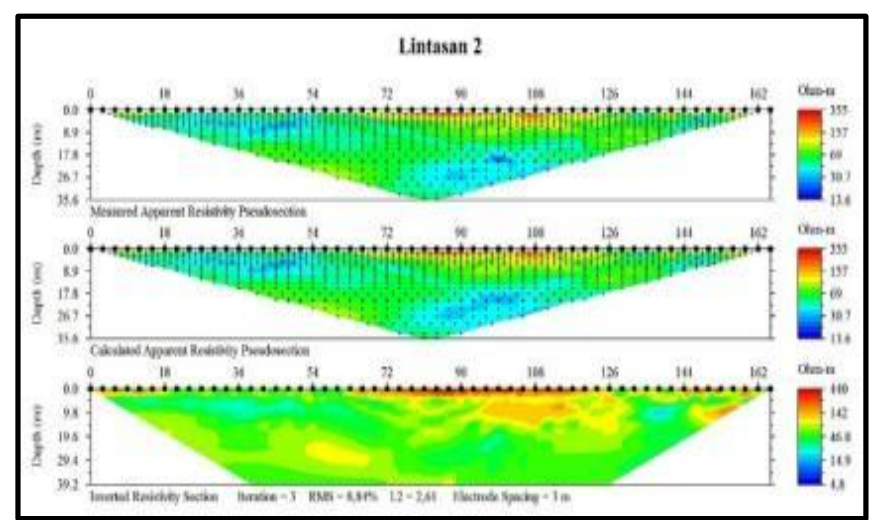

Gambar 6. Penampang 2D Hambatan Jenis Lintasan 2

Penampang 2D lintasan 2 (Gambar 6) menunjukkan bahwa nilai minimum hambatan jenis semu yang terukur dan terhitung sebesar 13,6 $\Omega \mathrm{m}$ sampai $355 \Omega \mathrm{m}$. Pada penampang hambatan jenis hasil pemodelan, diperoleh nilai minimum sebesar 4,8 $\Omega$ m dan maksimum $440 \Omega$ m. Nilai kesalahan yang diperoleh dari selisih hasil pengukuran dan hasil perhitungan sebesar $8,84 \%$ dengan 3 kali iterasi.

\section{Lintasan 3}

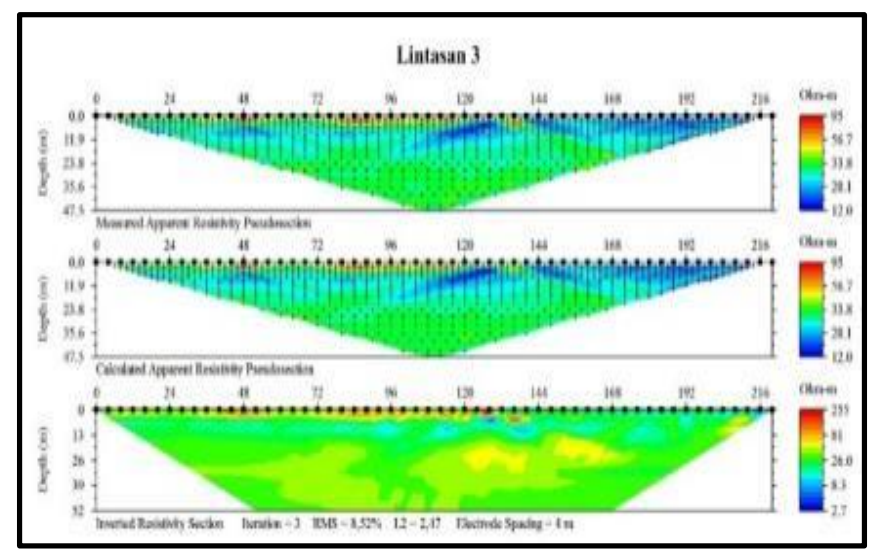

Gambar 7. Penampang 2D Hambatan Jenis Lintasan 3

Penampang 2D lintasan 3 (Gambar 7) menunjukkan bahwa nilai minimum hambatan jenis semu yang terukur sebesar 12,0 $\Omega \mathrm{m}$ dan maksimum $95 \Omega \mathrm{m}$. Nilai hambatan jenis sebenarnya hasil pemodelan sebesar $2,7 \Omega \mathrm{m}$ hingga $255 \Omega \mathrm{m}$. Nilai kesalahan yang diperoleh dari selisih hasil pengukuran dan hasil perhitungan yaitu 8,52\% dengan 3 kali iterasi.

\section{Lintasan 4}

Penampang 2D lintasan 4 (Gambar 8) menunjukkan bahwa nilai minimum hambatan jenis semu yang terukur dan terhitung sebesar 25,0 $\Omega \mathrm{m}$ dan maksimum $565 \Omega \mathrm{m}$. Penampang 2D hasil pemodelan menunjukkan nilai hambatan jenis sebenarnya sebesar $7,2 \Omega \mathrm{m}$ hingga $8729 \Omega \mathrm{m}$. Nilai kesalahan yang diperoleh dari selisih hasil pengukuran dan hasil perhitungan sebesar $8,39 \%$ dengan 4 kali iterasi.

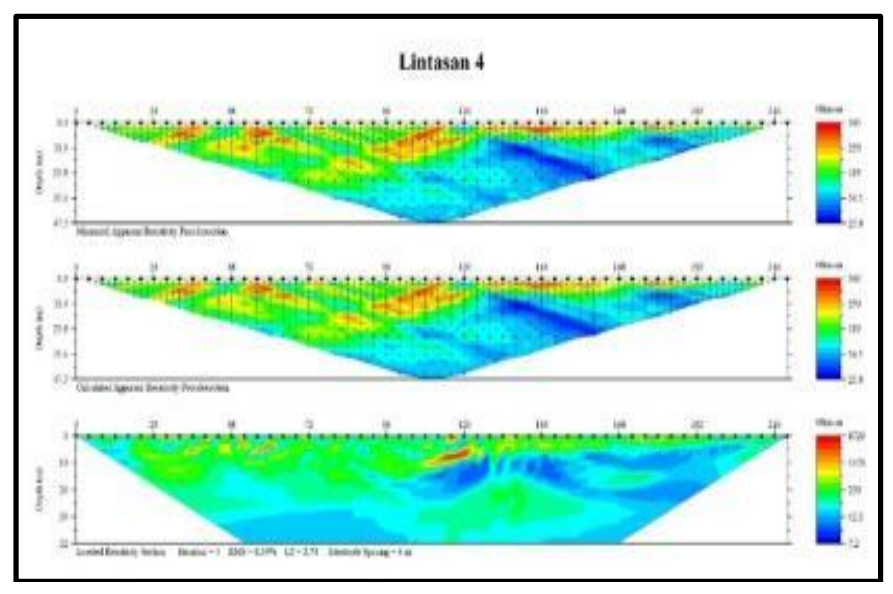

Gambar 8. Penampang 2D Hambatan Jenis Lintasan 4

Selanjutnya, dilakukan koreksi terhadap elevasi setiap elektroda, sehingga menghasilkan penampang yang telah terkoreksi topografi, kemudian menyeragamkan range hambatan jenis yang ditampilkan dengan nilai minimum sebesar $10 \Omega \mathrm{m}$ dan maksimum $300 \Omega \mathrm{m}$. Hal tersebut dilakukan karena pengukuran berada pada lokasi dan kondisi geologi yang sama (Gambar 1), serta merujuk pada tabel nilai hambatan jenis dan nilai faktor formasi batuan (Tabel 1) yang bergantung pada nilai hambatan jenis air pengisi pori di lokasi penelitian. Diketahui bahwa nilai hambatan jenis air pengisi pori berkisar 14,62 $\Omega \mathrm{m}$ hingga 15,90 $\Omega \mathrm{m}$. Gambar 9 - Gambar 12 merupakan tampilan hasil penampang 2D hambatan jenis yang telah terkoreksi topografi.

Agar mempermudah dalam tahapan interpretasi data, dibuat penampang 2D menggunakan Surfer 11 dengan data masukan berupa jarak (sumbu x), elevasi (sumbu y) dan nilai faktor formasi batuan (sumbu z). Dasar dalam menginterpretasikan hasil pengolahan data di daerah penelitian adalah nilai hambatan jenis setiap lintasan, data DHL dan kondisi geologi. Pada pengolahan data DHL, diperoleh nilai rata-rata hambatan jenis air pengisi pori $\left(\rho_{\mathrm{w}}\right)$ sebesar 15,46 $\Omega \mathrm{m}$. Berikut ini merupakan analisis lapisan berdasarkan nilai hambatan jenis yang diperoleh dari lokasi penelitian.

1. Lapisan 1 dengan nilai hambatan jenis $<30,92 \Omega$ m dengan faktor formasi $<2$ ditunjukkan dengan warna hijau muda sampai hijau tua. Lapisan ini diduga sebagai lapisan lempung dan lempung pasiran. Berdasarkan nilai faktor formasi yang diperoleh, lapisan ini bersifat akuiklud.

2. Lapisan 2 dengan nilai hambatan jenis $30,92-77,3 \Omega \mathrm{m}$ dengan faktor formasi 2-5 ditunjukkan dengan warna hijau kekuning-kuningan hingga warna kuning diduga sebagai lapisan pasir dan kerikil. Lapisan ini merupakan lapisan akuifer dengan permeabilitas sedang sampai tinggi.

3. Lapisan 3 dengan nilai hambatan jenis $>77,3 \Omega \mathrm{m}$ dengan nilai faktor formasi $>5$ ditunjukkan dengan warna merah. Lapisan ini diduga sebagai lapisan batupasir. 


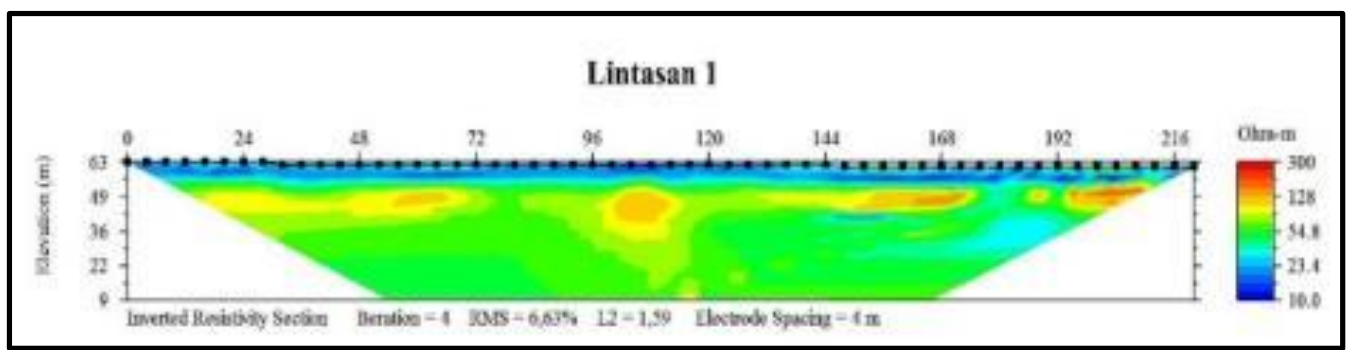

Gambar 9. Penampang 2D Hambatan Jenis dengan Koreksi Topograf pada Lintasan 1

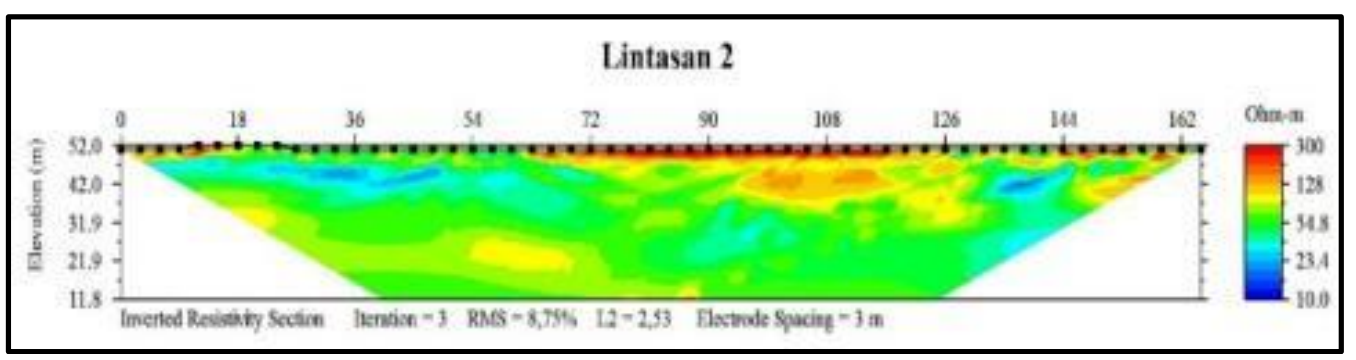

Gambar 10. Penampang 2D Hambatan Jenis dengan Koreksi Topografi pada Lintasan 2

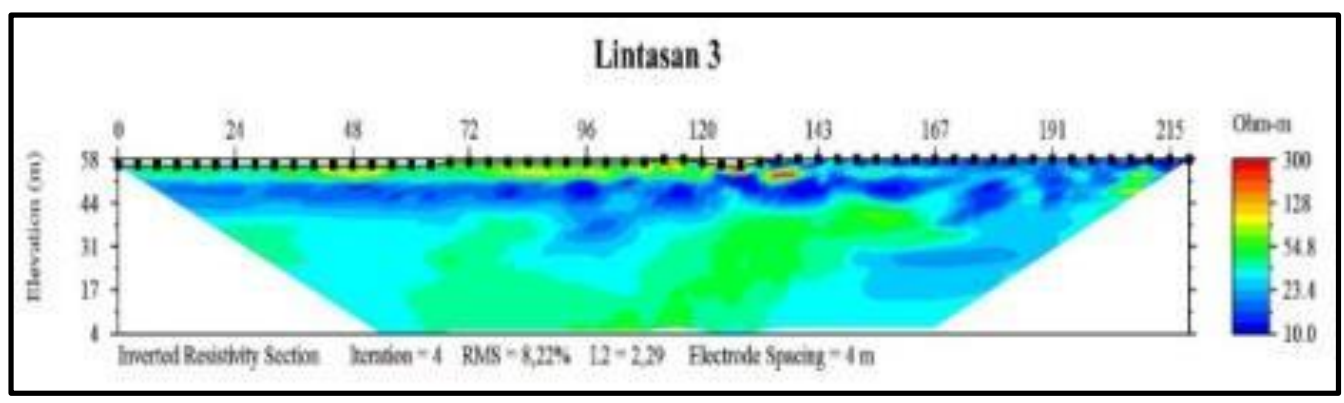

Gambar 11. Penampang 2D HambatanJenis dengan Koreksi Topografi pada Lintasan 3

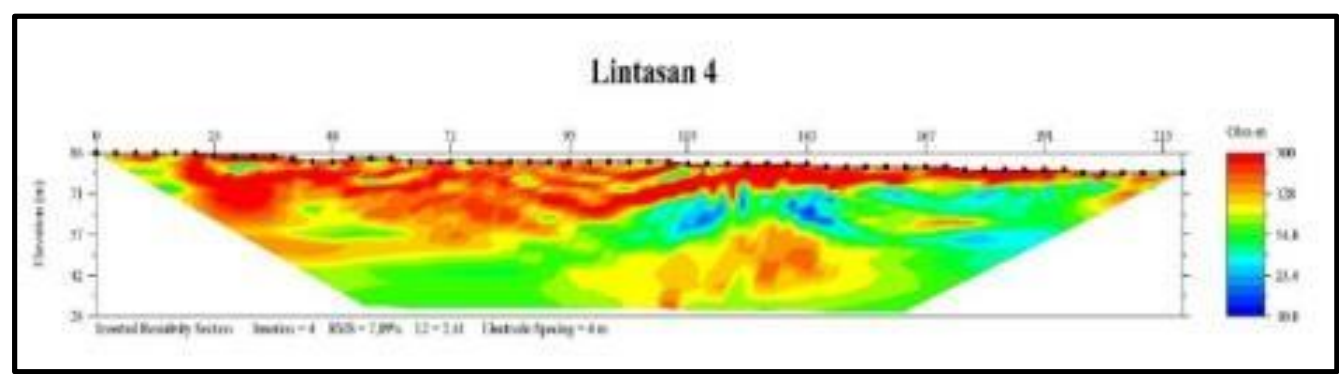

Gambar 12. Penampang 2D Hambatan Jenis dengan Koreksi Topografi pada Lintasan 4

Untuk memperoleh gambaran tentang lapisan akuifer bawah permukaan, maka keseluruhan penampang hambatan jenis diinterpretasikan melalui penampang faktor formasi berikut ini.

\section{Lintasan 1}

Lapisan akuifer berhambatan jenis 29,24-73,1 $\Omega \mathrm{m}$ dengan nilai faktor formasi $2-5$, terdeteksi pada kedalaman $\pm 4 \mathrm{~m}$ di bawah permukaan tanah dengan ketebalan lapisan $\pm 46 \mathrm{~m}$. Hal ini sesuai dengan kedalaman sumur bor yang berada di sekitar lintasan pengukuran dengan kedalaman sumur bor $\pm 9 \mathrm{~m}$ bmt. Pada bagian Barat Laut, di kedalaman $16 \mathrm{~m}$ terdapat lapisan akuifer yang bersifat poor aquifer. Dipermukaan, lapisan ini ditutupi oleh lapisan lempung yang telah ditumbuhi rumput seperti yang terlihat pada gambar. Lapisan lempung ini ditemui hingga kedalaman $\pm 4 \mathrm{~m}$. Selain itu, pada kedalaman 6 $\mathrm{m}$, lapisan akuifer disisipi oleh lapisan batuan yang diduga sebagai batupasir, dengan ketebalan antara 4-20 m.

\section{Lintasan 2}

Pada lintasan 2 (Gambar 14), lapisan akuifer berhambatan jenis 31,4-78,5 $\Omega \mathrm{m}$ dengan nilai faktor formasi $2-5$, terdeteksi pada kedalaman $\pm 4 \mathrm{~m}$ di bawah permukaan tanah dengan ketebalan $\pm 32 \mathrm{~m}$. Berdasarkan faktor formasi yang diperoleh, lapisan ini bersifat permeable dan merupakan lapisan akuifer dengan permeabilitas sedang sampai tinggi. Dipermukaan, lapisan yang memiliki nilai hambatan jenis sama dengan lapisan akuifer diduga merupakan lapisan pasir yang terkena resapan air bersumber dari daerah persawahan. Pada meteran 0 sampai 18, lapisan yang berwarna merah merupakan pasir 
kering hasil timbunan pembuatan jalan raya, seperti yang ditunjukkan oleh gambar yang berada di elektroda 1, dan pada meteran 60 hingga 165, lapisan yang ditandai oleh warna merah juga diduga sebagai pasir kering, dimana pada daerah tersebut merupakan daerah timbunan seperti terlihat pada gambar yang terletak di elektroda 53.

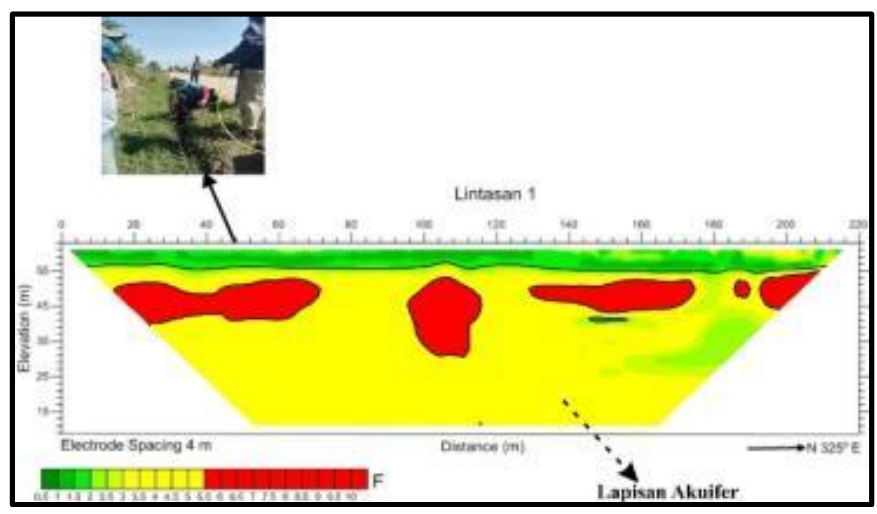

Gambar 13. Penampang 2D Faktor Formasi pada Lintasan 1

Lapisan akuifer pada meteran 5 hingga meteran 50, ditutupi oleh lapisan lempung dengan ketebalan $2 \mathrm{~m}$ hingga $4 \mathrm{~m}$. Pada meteran 132 hingga 144 disisipi oleh lapisan lempung dengan ketebalan $\pm 4 \mathrm{~m}$ dan pada meteran 54 sampai 69, kembali disisipi oleh lapisan yang diduga sebagai batupasir dengan ketebalan $\pm 4 \mathrm{~m}$. Pada meteran 54 hingga 69 , lapisan akuifer disisipi oleh lapisan batupasir dengan ketebalan berkisar $4 \mathrm{~m}$ sampai $6 \mathrm{~m}$. Pada penampang, menunjukkan kesesuaian data terhadap sumur bor dengan kedalaman $\pm 9 \mathrm{~m} \mathrm{bmt}$.

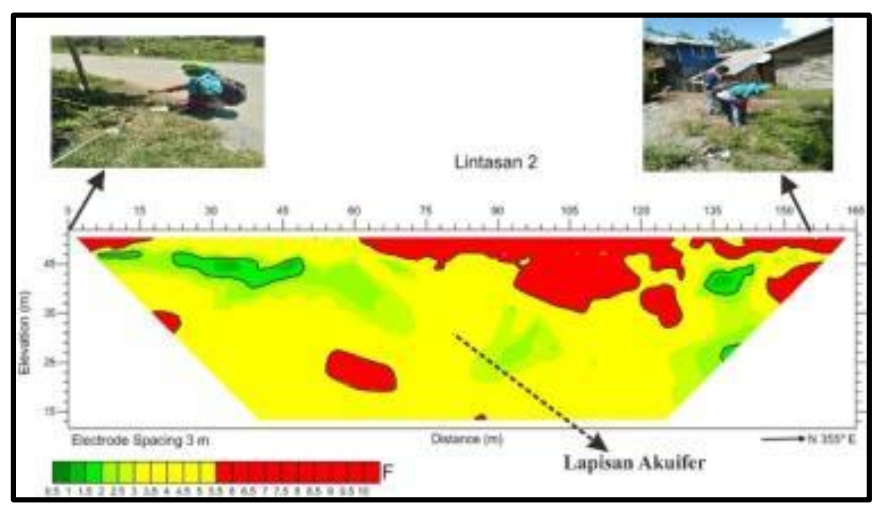

Gambar 14. Penampang 2D Faktor Formasi pada Lintasan 2

3. Lintasan 3

Lapisan akuifer yang berhambatan jenis $31,2-78 \Omega \mathrm{m}$ dengan nilai faktor formasi 2-5 terdeteksi pada kedalaman $11 \mathrm{~m}$ di bawah permukaan tanah dengan ketebalan $\pm 39 \mathrm{~m}$. Pada lintasan 3 ini, lapisan akuifer didominasi oleh akuifer yang bersifat poor aquifer. Lapisan ini ditutupi oleh lapisan lempung dengan ketebalan antara 11-31 m. Dipermukaan, pada meteran 0 sampai 120 , lapisan yang berhambatan jenis sama dengan lapisan akuifer diduga merupakan lapisan penutup berupa tanah lembab yang diduga sebagai resapan pembuangan air dari warga di sekitar lintasan pengukuran. Selain itu, dapat dilihat pada gambar, ditemui adanya bekas aliran air, sehingga tanahnya cukup lembab dan ditumbuhi oleh tanaman air. Pada lokasi lintasan ini memiliki data sumur bor dengan kedalaman $\pm 12 \mathrm{~m}$ bmt dan sesuai dengan hasil yang diperoleh pada penampang.

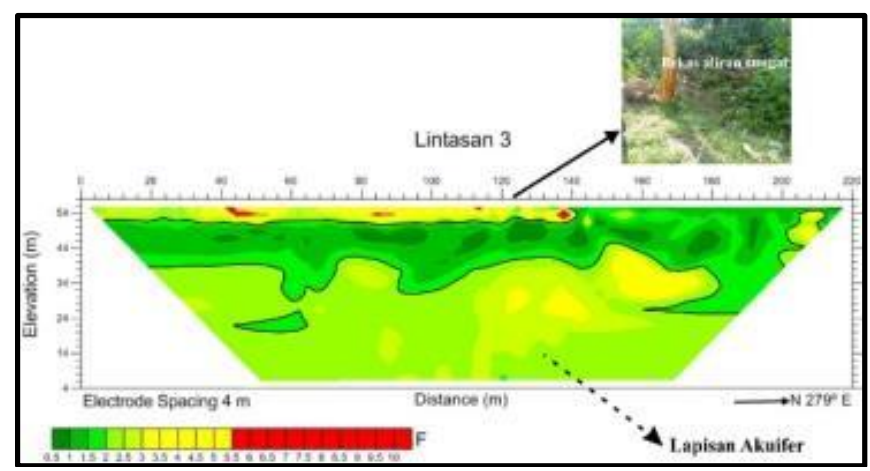

Gambar 15. Penampang 2D Faktor Formasi pada Lintasan 3

\section{Lintasan 4}

Pada lintasan 4 (Gambar 16), lapisan akuifer yang berhambatan jenis $31,8-79,5 \Omega \mathrm{m}$, terdeteksi pada kedalaman $4 \mathrm{~m}$ hingga $38 \mathrm{~m}$ dengan ketebalan yang bervariasi antara 16 $\mathrm{m}$ hingga $46 \mathrm{~m}$. Lapisan ini menebal dan mendangkal ke arah Barat, dimana pada bagian atas lapisan ini ditutupi oleh lapisan batupasir (lapisan berwarna merah) dengan kenampakan permukaan seperti yang terlihat pada gambar. Lapisan batupasir yang terdeteksi pada meteran 112, diduga merupakan hasil erosi dari bagian timur lintasan ketika terjadi likuefaksi. Selain itu, pada meteran 112 hingga 190, lapisan akuifer disisipi oleh lapisan lempung yang tidak menerus dengan ketebalan antara 2-12 m dan pada meteran 96 hingga 180, disisipi oleh lapisan yang diduga sebagai batupasir dengan ketebalan $2 \mathrm{~m}$ hingga $34 \mathrm{~m}$. Pada lokasi lintasan ini memiliki data sumur bor dengan kedalaman $\pm 28 \mathrm{~m}$ bmt, namun letak sumur cukup jauh dari lintasan pengukuran.

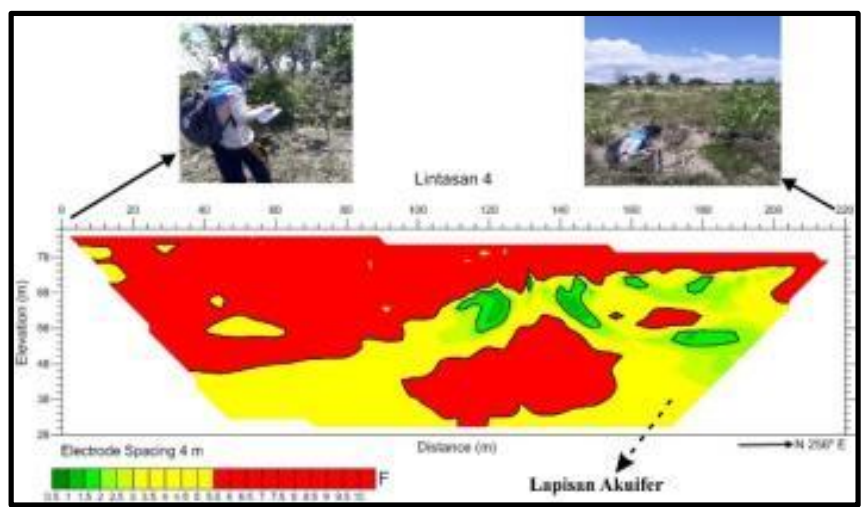

Gambar 16. Penampang 2D Faktor Formasi pada Lintasan 4

Berdasarkan hasil interpretasi keseluruhan penampang, lapisan akuifer yang diperoleh merupakan lapisan akuifer tak tertekan (unconfined aquifer), karena tidak ditemui adanya 2 lapisan impermeable yang mengapit lapisan tersebut. Lapisan akuifer ini tidak mengalami pergeseran atau perubahan kedalaman akibat adanya likuefaksi. Hal ini dikarenakan adanya kecocokan data kedalaman sumur bor warga dengan hasil interpretasi yang dilakukan.

\section{KESIMPULAN}

Berdasarkan hasil penelitian, dapat disimpulkan bahwa lapisan akuifer di Kelurahan Petobo memiliki nilai hambatan jenis yang berkisar antara 30,92-77,3 $\Omega \mathrm{m}$, diduga terdiri atas pasir dan kerikil dengan nilai faktor formasi 2-5 yang ditunjukkan oleh warna hijau kekuning-kuningan hingga warna kuning. 
Lapisan ini berada pada kedalaman yang bervariasi antara \pm 4 $\mathrm{m}$ hingga $\pm 38 \mathrm{~m}$ di bawah permukaan tanah dengan ketebalan yang berkisar $\pm 16 \mathrm{~m}$ hingga $\pm 46 \mathrm{~m}$. Lapisan akuifer mendangkal dan semakin menebal ke arah barat.

\section{REFERENSI}

[1] [BMKG] Badan Meteorologi, Klimatologi, dan Geofisika. (2018). Monitoring Gempa Bumi 28 September 2018. Diperoleh dari website. Badan Meteorologi, Klimatologi, dan Geofisika: http://www.bmkg.co.id/press-release/?p=gempabumi-tektonikm7-7-kabupaten-donggala-sulawesi-tengah-pada-hari-jumat-28september-2018-berpotensi-tsunami\&tag=pressrelease\&lang=ID.

[2] Kaharuddin, M. S., Hutagalung, R., dan Nurhamdan. (2011). Perkembangan Tektonik Dan Implikasinya Terhadap Potensi Gempa Dan Tsunami Di Kawasan Pulau Sulawesi. Prosiding $J C M$ (hal 1-10). Makasar.

[3] Lenggogeni, D., Wahab, H., Kuswiyanto, Aruminingsih, Jovel, M. R., Sagala, S., Parlan, H., Buamona, A., Novirianti, D., Syathiri, M., Ermanita, A., Roudo, M., Mariska, Hamzah, R., Dorodjatoen, M. H. A., Winata, S. E., Ruhama, T., Imanullah, M. Suek, J., Fausi, R. R. (2018). Rencana Induk Pemulihan dan Pembangunan Kembali Wilayah Pascabencana Provinsi Sulawesi Tengah. Palu: Kedeputian Bidang Pengembangan Regional, Kementerian PPN/Bappenas.

[4] Mina, E., Kusuma, R. I., dan Sudirman, S. (2018). Analisa Potensi Likuefaksi Berdasarkan Data SPT (Studi Kasusproyek Pembangunan Gedung Baru Untirta Sindang Sari). Jurnal Fondasi, 7(1), 11-21. https://doi.org/10.36055/jft.v7i1.3298.

[5] Yao, Y., Chen, J., Li, T., Fu, Bo., Wang, H., Li, Y., and Jia, H. (2019). Soil Liquefaction in Seasonally Frozen Ground During the 2016 Mw6.6 Akto Earthquake. Soil Dynamics and Earthquake Engineering, 117, 138-148.

[6] Hardy, T., Nurdiyanto, B., Ngadmanto, D., dan Susilato, P. (2015). Karakteristik Lapisan Tanah Berpotensi Likuefaksi Berdasarkan Hambatan jenis Batuan di Daerah Cilacap. Jurnal Meteorologi dan Geofisika, 16(1), 47-56.

[7] Wahyuni, D., Musa, M. D. Th., dan Sandra. (2018). Identifikasi Sebaran Lapisan Akuifer Menggunakan Metode Geolistrik Hambatan Jenis di Wilayah Kecamatan Ampibabo Kabupaten Parigi Moutong. Journal of Science and Technology, 7(11), 176186.

[8] Darsono. (2016). Identifikasi Akuifer Dangkal dan Akuifer Dalam dengan Metode Geolistrik. Indonesian Journal of Applied Physics, 6(1), 40-49.

[9] Purnama, Y., Jumarang, I. M., dan Muliadi. (2018). Identifikasi Jenis Akuifer di Kawasan Jungkat Menggunakan Metode
Geolistrik Resistivitas Konfigurasi Dipole-dipole. PRISMA FISIKA, 6(2), 101-107.

[10] Irawati, I., Rahman, Abd., dan Musa, M. D. (2016). Identifikasi Sebaran Aquifer Menggunakan Metode Geolistrik Hambatan Jenis Di Desa Bora Kecamatan Sigi Biromari Kabupaten Sigi. Journal of Science and Technology, 5(2), 223-233. https://doi.org/10.22487/25411969.2016.v5.i2.6709

[11] Sukamto, R. (1973). Peta Geologi Lembar Palu, Sulawesi, Skala 1:250.000. Bandung: Pusat Penelitian dan Pengembangan Geologi.

[12] Simpen, I. N., Redana, I. W., Pujianiki, Ni. N., and Umratul, I. (2017). Aquifers Selection to Aid Geoelectrical Methods on Drilled Well Building near the Beach. International Journal of Physical Sciences and Engineering, 1(3), 41-50.

[13] Santosa, W. L., dan Adji, N. T. (2014). Karakteristik Akuifer dan Potensi Air Tanah Graben Bantul. Yogyakarta: Gadjah Mada University Press.

[14] Azwar, H. (2009). Pemodelan Lapisan Air Tanah Dalam (Akuifer) di Desa Telogorejo Kab. Demak Berdasarkan Data Tahanan Jenis. Skripsi. Fakultas Sains dan Teknologi, Universitas Islam Negeri Syarif Hidayatullah. Jakarta.

[15] Simpen, I. N., Sutama, S. I. N., Redana, I. W., and Zulaikah, S. (2016). Aquifer Porosity Prediction Base on Resistivity Data and Water Conductivity. International Research Journal of Engineering, IT \& Scientific Research, 2(5), 7-16.

[16] Musa, M. D. Th. (2004). Pemetaan Sebaran Akuifer di Bagian Timur Cekungan Air Tanah (CAT) Gorontalo dengan Menggunakan Metode Geolistrik Hambatan Jenis. Tesis. Institut Teknologi Bandung. Bandung.

[17] Irwandy, A. (2016). Geoteknik Tambang. Jakarta: Gramedia Pustaka Utama.

[18] Adeeko and Samson. (2018). Application of Electrical Resistivity in Mapping. Asian Jounal of Environment \& Ecology, 6(1), 1-12.

[19] Sholichin, M. (2018). Panduan Penyelidikan Lapangan Hidrogeologi. Malang: Universitas Brawijaya Press.

[20] Telford, W.M., Sheriff, R.E., and Geldart, L. P. (1990). Applied Geophysiscs (2end ed.). New York: Cambridge University Press.

[21] Reynolds, J. M. (1997). An Introduction to Aplied and Environmental Geophysics. England: John Wiley and Sons Inc.

[22] Yulianto, T., Gernowo, R., and Krisna, W. (2016). The Determination of Slip Surface Layer in Trangkil Sttlement Area, Sukorejo Village, Gunungpati District, Semarang Municipality using Two Dimensional Resistivity Method with Dipole-dipole Configuration. International Journal of Applied Environmental Sciences, 11(6), 1363-1373. 